See Article page XXX.

\section{Commentary: Supervised autonomy does no harm}

\author{
Danial Ahmad, MD, and \\ Vakhtang Tchantchaleishvili, MD
}

Escorel Neto and colleagues ${ }^{1}$ present an important metaanalysis comparing outcomes between cardiac procedures performed by consultant/attending cardiac surgeons and those performed by trainees under their supervision. The authors found longer time on cardiopulmonary bypass (CPB) and longer aortic crossclamp time (AXC) but reduced mortality in trainee-led cases. The longer $\mathrm{CPB}$ and AXC time did not lead to longer lengths of stay. Other outcomes such as renal and sternal complications were comparable between the groups as well. ${ }^{1}$

In essence, with their data the authors have added more evidence to the notion that supervised resident physician autonomy in the operating room does not translate to worse outcomes. ${ }^{2,3}$ The results are also encouraging because they indicate that current and previous resident physicians have been able to safely operate under supervision. From this standpoint, longer CPB and ACX times likely represent surrogates of safety, implying that resident physicians are not being rushed to complete their tasks by potentially compromising on quality. Therefore, programs and attending physicians should be encouraged to let resident physicians take on increasingly complex and leading roles in surgeries, provided the trainees have been displaying increasing competency (Figure 1). Simulation training may also enhance learning by equipping resident physicians with the skills necessary to take on greater roles in the operating room. ${ }^{4}$ The responsibility is also on the trainees to utilize whatever resources are at their disposal to meet expectations in the operating room.

From the Division of Cardiac Surgery, Thomas Jefferson University, Philadelphia, Pa. Disclosures: The authors reported no conflicts of interest.

The Journal policy requires editors and reviewers to disclose conflicts of interest and to decline handling or reviewing manuscripts for which they may have a conflict of interest. The editors and reviewers of this article have no conflicts of interest.

Received for publication Dec 21, 2021; revisions received Dec 21, 2021; accepted for publication Dec 22, 2021.

Address for reprints: Vakhtang Tchantchaleishvili, MD, Division of Cardiac Surgery, Thomas Jefferson University, 1025 Walnut St, Suite 607, Philadelphia, PA 19107

(E-mail: Vakhtang.Tchantchaleishvili@jefferson.edu).

J Thorac Cardiovasc Surg 2022; $\mathbf{\square}: 1-2$

$0022-5223 / \$ 36.00$

Copyright $(2022$ by The American Association for Thoracic Surgery

https://doi.org/10.1016/j.jtcvs.2021.12.041

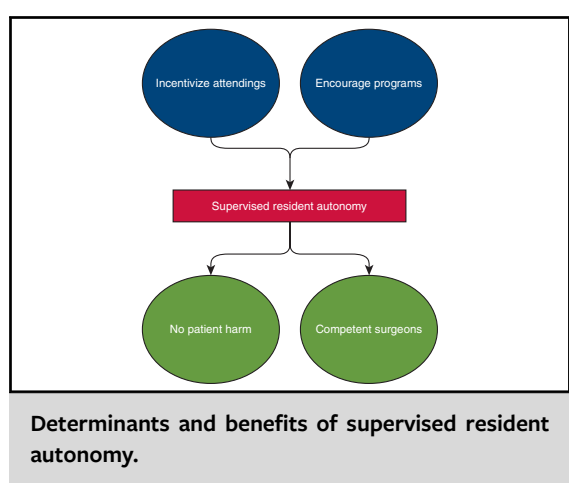

\section{CENTRAL MESSAGE \\ Cardiothoracic surgery trainees can safely perform surgeries un- der attending supervision. This supervised autonomy is essential for training competent cardio- thoracic surgeons of the future.}

This study also raises an interesting question about what a trainee-led case really is. There is discrepancy between programs relating to degree of resident autonomy and the type of cases they perform. The definition of autonomy

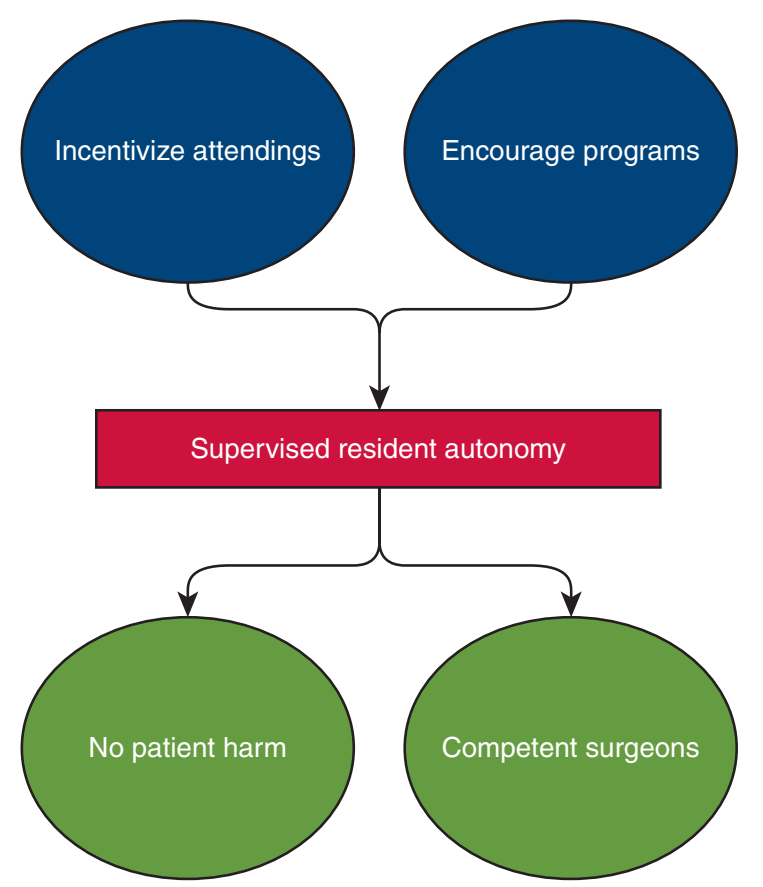

FIGURE 1. Determinants and benefits of supervised resident autonomy. 
has, at best, been evolving. Although this may be hard to quantify, it speaks to the need for standardization of case $\operatorname{logs}$ and open communication between trainees and their attending surgeons to ensure competence upon graduation. ${ }^{5}$

The findings should also be seen in the context of increased reporting of surgeon-specific outcomes and the associated payment models. While not sacrificing outcomes, an attending has to be able to give his or her trainee increasingly complex tasks in the operating room. It may be worth incentivizing training for attending surgeons because not all good surgeons are good teachers. Rather than mandating that every attending physician must train residents independent of their level of voluntary involvement, it may be better to have separate accreditation for attending physicians who train residents. Training cases could then be incorporated separately into the payment model, thus removing some barriers to better training of physicians during residency. ${ }^{3}$

Training in cardiothoracic surgery is complex due to the technical nature of the procedures, the different training pathways, and the length and intensity of training. ${ }^{6}$ What's at stake here is patient welfare-be it today with good surgeons, or tomorrow with well or poorly trained ones.
The latter is where most work can be done. The findings of this study should not be taken lightly because resident training is the backbone of cardiothoracic surgery's future.

\section{References}

1. Escorel Neto AC, Pompeu Sá M, Van den Eynde J, Rotbi H, Do-Nguyen CC, Olive JK, et al. Outcomes of cardiac surgical procedures performed by trainees versus consultants: a systematic review with meta-analysis. $J$ Thorac Cardiovasc Surg. 2022;XXX:XXX.

2. Szczechowicz MP, Easo J, Zhigalov K, Mashhour A, Mkalaluh S, Weymann A. Training of residents in cardiac surgery-does it have impact on the outcome? Thorac Cardiovasc Surg. 2021;69:13-8. https://doi.org/10.1055/s-0039-3400263

3. Luthra S, Leiva-Juarez MM, Ismail A-H, Tsang GM, Barlow CW, Velissaris T, et al. Is resident training safe in cardiac surgery? Ann Thorac Surg. 2020;110: 1404-11. https://doi.org/10.1016/j.athoracsur.2020.02.009

4. Moorjani N, Lewis M, Shah R, Barnard S, Graham T, Rathinam S. Implementation of a novel portfolio of structured, curriculum-aligned, simulation-based, cardiothoracic surgery training courses: evolving the delivery of surgical education. J Thorac Cardiovasc Surg. 2017;154:2009-16. https://doi.org/10.1016/j.jtcvs. 2017.07.075

5. Shah AA, Aftab M, Tchantchaleishvili V, LaPar DJ, Stephens EH, Walters DM, et al. Characterizing the operative experience of cardiac surgical trainees: what are residents really doing in the operating room? Ann Thorac Surg. 2016;101: 2341-9. https://doi.org/10.1016/j.athoracsur.2015.12.069

6. Vaporciyan AA, Yang SC, Baker CJ, Fann JI, Verrier ED. Cardiothoracic surgery residency training: past, present, and future. J Thorac Cardiovasc Surg. 2013;146: 759-67. https://doi.org/10.1016/j.jtcvs.2013.06.004 